IZA DP No. 4542

The Timing of Work and Work-Family Conflicts in Spain: Who Has a Split Work Schedule and Why?

Catalina Amuedo-Dorantes

Sara de la Rica

November 2009 


\title{
The Timing of Work and Work-Family Conflicts in Spain: Who Has a Split Work Schedule and Why?
}

\author{
Catalina Amuedo-Dorantes \\ San Diego State University, \\ CReAM, FEDEA and IZA \\ Sara de la Rica \\ Universidad del País Vasco, \\ FEDEA, CReAM and IZA \\ Discussion Paper No. 4542 \\ November 2009 \\ IZA \\ P.O. Box 7240 \\ 53072 Bonn \\ Germany \\ Phone: +49-228-3894-0 \\ Fax: +49-228-3894-180 \\ E-mail: iza@iza.org
}

Any opinions expressed here are those of the author(s) and not those of IZA. Research published in this series may include views on policy, but the institute itself takes no institutional policy positions.

The Institute for the Study of Labor (IZA) in Bonn is a local and virtual international research center and a place of communication between science, politics and business. IZA is an independent nonprofit organization supported by Deutsche Post Foundation. The center is associated with the University of Bonn and offers a stimulating research environment through its international network, workshops and conferences, data service, project support, research visits and doctoral program. IZA engages in (i) original and internationally competitive research in all fields of labor economics, (ii) development of policy concepts, and (iii) dissemination of research results and concepts to the interested public.

IZA Discussion Papers often represent preliminary work and are circulated to encourage discussion. Citation of such a paper should account for its provisional character. A revised version may be available directly from the author. 
IZA Discussion Paper No. 4542

November 2009

\section{ABSTRACT \\ The Timing of Work and Work-Family Conflicts in Spain: Who Has a Split Work Schedule and Why?*}

Spain, as other south-Mediterranean countries, is characterized for the predominance of split work schedules. Split work schedules typically consist of 5 hours of work in the morning (typically from 9 am to $2 \mathrm{pm}$ ), followed by a 2 hour break and another 3 hours of work in the afternoon/evening (typically from $4 \mathrm{pm}$ to $7 \mathrm{pm}$ ). Because of the evening work hours, split work schedules are contributing to work-family conflicts in the midst of significantly higher female labor force participation. Our purpose is to examine who has a split work schedule and why. We focus on full-time working women with full-time working partners, for whom the need to reconcile work and family responsibilities is likely to be more pressing. We first find that women with partners with a split work schedule or without children (less than 20 percent our sample) are more likely to have a split work schedule. Yet, despite the revealed preference for a continuous work schedule of the remaining women in our sample, we fail to find evidence of a compensating wage differential for having a split work schedule. We thus examine why and find that younger and less educated women more likely to be constrained in their job choices are more likely to work in the private sector, where split work schedules are primarily found.

JEL Classification: J16, J31, J81

Keywords: work-family conflicts, timing of work, split/continuous time schedule, compensating wage differentials, job constraints

Corresponding author:

Sara de la Rica

Universidad del País Vasco

Depto. Fundamentos del Análisis Económico II

Avenida Lehendakari Aguirre 83

48015 Bilbao

Spain

E-mail: sara.delarica@ehu.es

\footnotetext{
* We are grateful to Manuel Arellano and to participants in the COSME workshop at the Bank of Spain in May 2009.
} 


\section{Introduction}

“En España, los horarios laborales son machistas”

"In Spain, the workplace time Schedule is sexist"

\section{Ignacio Buqueras \\ Presidente de la Comisión Nacional para la Racionalización de Horarios Interview at www.nortecastilla.es, April 11, 2008}

Conflicts between work and family responsibilities are rising in many countries as a result of changes in family structures and in the work environment ranging from increased female labor force participation to limited availability of family assistance, expensive child care options and increased levels of travel time and stress. These conflicts can cause major problems for families, who have a hard time organizing family schedules, as well as for firms and society as a whole via the under-utilization of women's skills, low fertility in industrialized economies, or increased economic vulnerabilities of many families. ${ }^{1}$ Hence, there is a growing interest in learning about labor market policies that may help reconcile family and work responsibilities, particularly for women with family responsibilities (see Lanfranchi et al., 2002, Rapoport et al., 2008, Hamermesh and Donald, 2007).

We look at the conflict between family and work responsibilities created by the timing of work in a large number of jobs in Spain as the fraction of working women has almost doubled over the past two decades. ${ }^{2}$ Spain is one of the south-Mediterranean countries characterized for having a widely spread split work schedule that conflicts with family responsibilities by having a long lunch break in the middle of the workday. The split work schedule typically consists of 5 hours of work in the morning (typically from 9 am to $2 \mathrm{pm}$ ), followed by a 2 hour break in the middle of the day and another 3 hours of work in the afternoon/evening (typically from $4 \mathrm{pm}$ to $7 \mathrm{pm}$ ). The two-hour break in the middle of the day was intended to accommodate the main meal, which typically took place at home with all

\footnotetext{
${ }^{1}$ See Hein (2005) for a detailed coverage of the various implications of work and family conflicts for families, firms and societies as a whole.

${ }^{2}$ Since the early eighties, about 3.7 million of Spanish women have entered the labor market.
} 
the family. Because female labor force participation was very low, split work schedules did not seem to interfere with the ability of taking care of other family responsibilities carried out by stay-home women, such as preparing the main meal of the day, picking up children from school or caring for them during the late afternoon and early evening. Nevertheless, this has changed over the past two decades as female labor force participation rates -particularly among women in childbearing age- have increased by 20 percentage points. Yet, split work schedules continue to be quite prevalent. As a result, working men and, particularly, working women performing the lion's share of household work are having an increasingly difficult time in reconciling family and work responsibilities. ${ }^{3}$

The purpose of this paper is to gain a better understanding of who has a split work schedule and why. Specifically, if split work schedules conflict with family responsibilities, why do some women choose them? Are these women voluntarily choosing a split work schedule as hedonic wage theory would argue? And, in that case, are they doing so in exchange for a compensating wage differential? Or is their work schedule choice constrained owing to the lack of alternative employment opportunities with more convenient work schedules as segmented labor market theory would suggest?

To address the aforementioned questions, we focus on individuals for whom the need to reconcile work and family responsibilities is more pressing, such as full-time working couples and, in particular, women. ${ }^{4}$ We use data from the Spanish Time Use Survey. This is part of the Harmonized European Time Use Survey initiated in 2002-2003 by Eurostat. The main advantage of this database, as compared to other micro-databases, is that each participant records her/his hours of work in a weekly diary as well as her/his activities in each 10-minute interval during a 24-hour "normal day” diary. Hence, in addition to respondents'

\footnotetext{
${ }^{3}$ Approximately 75 percent of women continue to do the lion's share of home production, including caring for children and elderly members due, in part, to tougher to change cultural and societal norms (Fernandez and Sevilla 2009).

${ }^{4}$ Nonetheless, we also look at other demographic groups as a robustness check.
} 
self-reported information on the type of work schedule they have, we are able to measure fairly precisely hours of work and the timing of work using data from the weekly diary and the 24-hour diary of activities. Finally, because we also have information on the respondent's human capital and job related characteristics, including the net monthly salary, we are able to examine if workers are receiving a compensating wage differential for having a more inconvenient split work schedule or not.

In what follows, we first describe the institutional framework of the Spanish labor market and some of its characteristics, which prove crucial in understanding our findings. In section 3, we describe the data, our sample of analysis, and provide some descriptive evidence on the incidence of split work schedules in Spain. We then proceed to the core of our study in section 4. We explain our methodology for examining who are the employees with a split work schedule and understand why they have that work schedule. We also discuss our results and robustness checks. Section 5 puts our findings in perspective with a discussion of the potential reasons behind our findings and Section 6 concludes the study.

\section{Institutional Background}

Before proceeding any further, it is important to discuss some of the institutional features of the Spanish labor market. Specifically, we focus on some characteristics crucial in understanding who has a split work schedule and why, such as traditionally high unemployment rates, limited job mobility, and centralized wage setting.

Spain has traditionally endured two-digit figure unemployment rates. During the time period being examined herein (i.e. 2002 and 2003), unemployment rates reached 11 to 12 percent of the labor force. These figures were approximately 16 percent in the case of women. $^{5}$ Additionally, Spain is characterized for having a very large proportion of workers in fixed-term contracts characterized by their short duration and inexistent job security

\footnotetext{
${ }^{5}$ Figures available at: www.ine.es
} 
relative to open-ended work contracts. ${ }^{6}$ High unemployment rates and a high rate of fixedterm employment help explain why many workers prefer a public sector job characterized by greater job security and often higher hourly wages. This is particularly true among women, as revealed by their higher presence in that sector compared to that of men. ${ }^{7}$ Once workers get a public sector job, they are reticent to move to another job for fear of losing their gained job security.

In addition to high unemployment rates and a high rate of fixed-term employment, job mobility is further constrained by the limited geographic mobility of Spanish workers. As noted by Bentolila (2001), internal migration rates in Spain have been traditionally low relative to those exhibited by other developed economies despite significant differences in per capita income and unemployment rates across regions. This is particularly true in the case of second-income earners in the household who, as such, are often restricted in their job mobility (i.e. they become tied-stayers).

Finally, Spain is also characterized for having a relatively centralized wage and working-conditions setting. Trade unions, along with employer organizations, negotiate wages, working hours and work incentives for the vast majority of Spanish workers. Despite having a low union density, the effective unionization rate (i.e. the proportion of workers represented by unions in collective bargaining) in Spain is quite high, with more than 80 percent of workers having their employment conditions regulated by a collective bargaining agreement (Jimeno and Toharia 1993). As a result, the existence of a compensating wage differential for an inconvenient work schedule is conditioned, to a large extent, on whether it has been negotiated in the corresponding collective bargaining agreement.

\footnotetext{
${ }^{6}$ Approximately one third of the workforce is on temporary contracts since the mid 1980s (www.ine.es). ${ }^{7}$ About 18 percent of working women, as opposed to 11 percent of working men, had a job in the public sector in 2008 (www.ine.es).
} 


\section{The Data}

As noted in the Introduction, we use data from the Spanish Time Use Survey (STUS). This dataset is part of the Harmonized European Time Use Survey (HETUS) carried out by Eurostat. The STUS contains a wide range of information on roughly 20,000 household (e.g. household composition and income, use of domestic service, and region of residence) and each of their members (e.g. demographic and labour market characteristics, including net monthly salaries). Crucial to this study is the fact that, in addition to the usual demographic and job characteristics, the STUS contains: (a) information on the respondent's work schedule, i.e. whether it is a continuous or a split work schedule; (b) information on the respondent's exact work hours from two sources: (i) a 24-hour diary detailing their activities in 10-minute intervals throughout a typical week day, and (ii) a weekly diary recording their exact hours of work in a standard work week; and (c) information on the respondent's net monthly salary..$^{8}$

As noted earlier, split work schedules are somewhat characteristic of Southern European countries like Spain. The HETUS website allows us to look at the percentage of individuals that report being at work as their primary activity during each of the 10-minutes' intervals of a standard day. Differences between Nordic countries -such as Norway, MidEuropean countries -like the United Kingdom, and Southern European countries -such as Spain, are displayed in Figures 1A-1C. In the Spanish case, one can detect a clear dip in the middle of the day that has much to do with the predominance of split work schedules in the country.

\footnotetext{
${ }^{8}$ One drawback of the STUS is that the information on the respondent's net monthly salary is recorded in intervals of 500 Euros. There are seven possible intervals: less than 500, 500-1000, 1001-1500, 1501-2000, 2001-2500, 2501-3000 and 3000 plus. This may create measurement errors, particularly at the two tails of the earnings distribution. Fortunately, only 1.3 percent of our sample falls within those tails. Therefore, for the computation of hourly wages, we use the middle point of the net monthly wage interval and divide it by the exact number of hours worked according to the information available in the weekly diary.
} 


\subsection{Sample of Study}

Given the purpose of our study, e.g. to learn about who chooses a split work schedule and why given the difficulty in reconciling family and work responsibilities in that event, we focus our attention on those individuals for whom the need to reconcile work and family responsibilities is more pressing, such as full-time working couples 16 to 65 years of age. This results in a sample of 1059 couples. While single individuals may also have family responsibilities potentially conflicting with their work schedules, such as taking care of children or elderly parents, this is a much smaller group than the one object of study and one that deserves a separate analysis due to their distinct personal circumstances. ${ }^{9}$ Additionally, the focus on couples allows us to use the partner's employment characteristics as instruments for the type of work schedule held by the worker albeit potential assortative mating issues (e.g. Olson 2002).

We gather information on the respondent's work schedule from two different sets of questions in the survey. First, the STUS asks all working respondents the following question: “Do you have a continuous or a split work schedule?” Second, the STUS has the information on the respondent's time work schedule from the 24-hour diary detailing their activities in each 10-minute interval of a typical day. To start with, we make use of the first and more direct source of information from the respondent. Later on, we also make use of respondents' 24-hour diary data to gain more insights about the exact timing of their work. After all, not all split work schedules are the same. Some workers with split work schedules may enjoy a midday break for lunch and still finish their workday by 5 p.m., as is the case with school teachers. In those instances, it is easier to reconcile work and family responsibilities. Therefore, as a robustness check, we also carry out the analysis with alternative definitions of a split or, more accurately, an inconvenient work schedule.

\footnotetext{
${ }^{9}$ This is a small, yet quite diverse sample that includes single parents as well as separated, divorced or widowed individuals - without even entering into other cases such as those of children caring for elderly parents. To preserve the homogeneity of the sample, we restrict the analysis to couples.
} 
Table 1 provides us with a quick glance at some of the personal and job related characteristics of the 1059 full-time working women and their male partners. In general, women are slightly younger and more educated than their male counterparts. About 69 percent of men and women in our sample have children. Yet, women are more likely than men to have a continuous work schedule and to work in the public sector, hinting on their employment preferences. Finally, women earn significantly less than men.

\subsection{Some Descriptive Evidence}

Table 2 displays the incidence of split work schedules among men and women in our sample according to personal and work-related characteristics. A few facts are worth noting:

1. The incidence of split work schedules is generally higher among younger workers. This is particularly true in the case of women, for whom the incidence of split work schedules drops by more than 10 percentage-points (from 47 percent among 16 to 30 year-old workers to 35 percent or less among older female employees).

2. Educational attainment reduces the incidence of a split work schedule among women, but the opposite is true among men. About 50 percent of male workers with a university degree have a split work schedule as opposed to 47 percent of male workers with a lower educational attainment.

3. Split work schedules are more common among male and female workers without children. This is particularly noticeable in the case of women, for whom the incidence of a split work schedule drops from 41 percent among non-mothers to approximately 33 percent among mothers.

4. Split work schedules are characteristic of the private sector, where 60 percent of men and 46 percent of women have this type of work schedule. In contrast, only 21 percent of men and 17 percent of women in the public sector have a split work schedule. 
5. Split work schedules are the norm in some industries, such as construction and trade, whereas the opposite is the case in domestic and personal services, despite significant differences by gender. By occupation, split work schedules are the norm among managers, but seem less likely among clerical support, service and sales workers. Among women, split work schedules are also fairly uncommon among professionals, plant/machine operators and assemblers and low-skilled workers.

Due to the very significant difference in the incidence of split work schedules in the public and private sectors, Table 3 further examines the characteristics of workers with split work schedules in both sectors. Split work schedules in the public sector are almost exclusive of highly qualified workers, i.e. professionals. However, in the private sector, split work schedules are spread among workers of distinct educational attainment levels, from highly skilled to less skilled workers, as in the case of craft and related male employees or service and sales female employees.

Finally, are workers with a split work schedule compensated for the disutility of having a more inconvenient work schedule? Using the information on the exact number of hours worked available in the weekly diary, we construct a measure of hourly wages and compute average hourly wages for various groups of workers in Table $4 .{ }^{10}$ Within the private sector, where the incidence of split work schedules is higher, female employees earn on average slightly more if they have a split work schedule. However, in the case of men, this is true only in the public sector, where the incidence of split work schedules in the public sector is negligible except among highly qualified workers.

Summarizing, the figures in Tables 2 through 4 reveal that split work schedules are less common among women. Additionally, within that group, split work schedules are more

\footnotetext{
${ }^{10}$ Due to the potentially different number of hours worked in public versus private sector jobs and even in continuous versus split work schedules, it is important to be able to gather information on the exact number of hours worked when constructing hourly wages. We are grateful to Daniel Fernandez for helping us to gather this information from the weekly diary.
} 
likely observed among younger, less educated or childless women. Split work schedules are also a feature of the private sector and the norm in industries such as domestic and personal services. In the private sector - where most jobs with split work schedules are concentrated, split work schedules are primarily concentrated among technicians and professionals, craft and related male workers and service and sales female employees. Furthermore, women with split work schedules in the private sector earn on average slightly more than those with a continuous shift, which could be the result of a compensating wage differential for the disutility resulting from having a more inconvenient work schedule.

Does this wage differential prevail when we control for these women's personal and job characteristics? To address this question, we start by estimating a benchmark log hourly wage regression for the samples of men and women in the public and private sectors. Hence, as a first step, we assume that the type of work schedule is exogenous and estimate the following model:

$$
\ln W_{i}=\beta_{0}+\beta_{1} S S_{i}+X_{i} \beta_{2}+\varepsilon_{1, i}
$$

where SS is the dichotomous variable indicating if the respondent has a split schedule. The results from this empirical exercise are displayed in Table 5. Private sector female employees with split work schedules no longer appear to be compensated for the disutility of having a more inconvenient work schedule. Instead, they earn 8 percent less than their counterparts with a continuous work schedule. Yet, to the extent that we are not taking into account the potential endogeneity of the type of work schedule held by the worker, these OLS results could be biased. In particular, if more able male and female employees not only earn higher wages but also choose more convenient work schedules, the compensating wage differential associated to having a split work schedule -a work schedule relegated to less able employees with lower earnings- is likely to be under-estimated. In what follows, we will address this limitation with a more thorough empirical analysis. 


\section{Who Chooses a Split Work Schedule and Why?}

Some women with partners with similar work schedules or without children may be indifferent between having a split as opposed to a continuous work schedule. However, women with greater family responsibilities are likely to regard having a split work schedule as a disutility as it will likely interfere with other daily child care chores, such as picking up children from school. Nevertheless, these married women with greater family responsibilities may still have a split work schedule, either voluntarily or involuntarily. If they choose to have a split work schedule voluntarily, they may do so with the expectation of being compensated for the disutility of having an inconvenient work schedule as would be predicted by the hedonic wage theory. Alternatively, women with greater family responsibilities may take a job with a split work schedule involuntarily due to their inability to find a similar job with a more convenient work schedule. This employment constraint may be the result of limited job mobility owing to high unemployment rates and restricted geographic mobility, both characteristics of the Spanish labor market. In both instances, lack of job choices makes the negotiation of a compensating wage differential implausible.

In what follows, we examine whether, once we account for the endogeneity of the type of work schedule held, having a split work schedule is accompanied by a compensating wage differential as would be expected if women prefer a continuous work schedule and have a split work schedule voluntarily.

\subsection{Methodology}

Standard compensating wage theory applied to the timing of work would predict that individuals might differ in their demand for jobs with more convenient work schedules and sort themselves across firms so as to find a job offering the wage and work schedule that suits them best. In that regard, once we account for all personal, human capital and job related characteristics impacting wages, workers with more inconvenient split work schedules should 
be compensated for the disutility imposed with a higher pay. A naïve way of estimating such a compensating wage differential is via the estimation of simple log hourly wage regression by OLS as in Table 5. Yet, as noted earlier, the coefficient on the dummy variable indicating whether the worker has a split work schedule is likely to be biased due to the endogeneity resulting from the existence of unobserved characteristics affecting wages and correlated with the likelihood of having a split work schedule -such as workers' productivity in analyses using cross-sectional data (Hwang et al. 1992).

Additionally, the estimation of equation (1) does not take into consideration the dynamics involved in choosing a particular work schedule. Instead of choosing a particular type of work schedule, workers typically choose the sector of employment (public versus private) first. If they are able to get a job in the public sector -a preferred sector due to its higher job security and often enough higher hourly wages, their work schedule is most likely a continuous one. After all, approximately 90 percent of workers in the public sector enjoy a continuous work schedule. Therefore, the choice of work schedule generally materializes for individuals employed in the private sector, where the fraction of male workers and female workers 35 to 65 years of age with a continuous work schedule is just 50 and 66 percent, respectively. Consequently, instead of simply restricting our attention to that group as in Table 5, we first model the worker's sector choice as follows:

$$
s=\operatorname{Pr}\left(\text { private }_{i}=1\right)=1\left[\gamma_{0}+\gamma_{1} \text { private }_{i}^{\text {Partner }}+Y_{i} \gamma_{2}+\varepsilon_{3, i} \geq 0\right]
$$

where $s=1$ if we observe wages in the private sector ( $W^{\text {private }}$ ) and zero otherwise. The variable private $_{i}^{\text {Parner }}$ informs about the partner's sector of employment and $Y$ is a vector of personal and work-related characteristics shaping the respondent's choice of employment sector. We check that the type of sector where the partner is employed serves as a good identifier in equation (2). That is, we check that it is helpful in explaining the sector choice of the respondent -which can be gauged from its statistical significant in the last column of 
Table 6- and that it is not statistically significant in explaining the respondent's log hourly wages or type of work schedule. ${ }^{11}$ We then estimate the $\gamma$ coefficients by Probit of $s$ on $Y_{i}$ and private $_{i}^{\text {Partner }}$ using our sample of women. We construct the inverse Mills ratio $\left(\lambda_{i}^{\text {private }}\right)$, which we include in the following system of equations estimated via instrumental variable methods:

$$
\ln W_{i}^{\text {private }}=\beta_{0}+\beta_{1} S S_{i}^{\text {private }}+X_{i}^{\text {private }} \beta_{2}+\beta_{3} \lambda_{i}^{\text {private }}+\varepsilon_{1, i}^{\text {private }}
$$

where: $W_{i}^{\text {private }}$ are the wages earned by the respondent in the private sector and $S S_{i}^{\text {private }}$ stands for the type of work schedule held by the private sector worker, which is instrumented in a first-stage regression as follows:

$$
\operatorname{Pr}\left(S S_{i}^{\text {private }}=1\right)=\alpha_{0}+\alpha_{1}\left(S S_{i}^{\text {Partner }}\right)+Z_{i}^{\text {private }} \alpha_{2}+\alpha_{3} \lambda_{i}^{\text {private }}+\varepsilon_{2, i}^{\text {private }}
$$

where: $S S_{i}^{\text {Partner }}$ is a dummy indicative of the partner's work schedule. The vectors $X$ and $Z$ contain the same personal and work-related characteristics included in $Y$ in equation (2) and influencing the employment outcomes being measured. Additionally, standard errors are bootstrapped.

As described by equation (4), the employee's work schedule choice is instrumented using information on the partner's work schedule based on the intrinsic value to couples of spending time together (Hamermesh 2000). The validity of our instrument relies on the correlation between both variables, which we find to be quite high, ${ }^{12}$ and on the absence of assortative mating. The latter could occur if low-wage men are not only more likely to marry low-wage women but, in addition, low wages are correlated with split work schedules. In

\footnotetext{
${ }^{11}$ Results for the 1059 full-time working women in our sample, our primary group of interest, are shown in Table A in the appendix.

${ }^{12}$ We check the correlation of our instrument with the individual's choice of a job with a split work schedule the endogenous regressor to be instrumented. The problem of "weak instruments" arises when either the instruments are weakly correlated with the endogenous regressor or the number of instruments is too large (Angrist and Krueger 2001). The first stage regression results indicates that the spouse's work schedule is statistically significant (at the 5 percent level) in explaining the respondent's work schedule. This is also found to be true for other demographic groups we examine later, such as mothers and married men.
} 
that case, the negative correlation between $S S^{\text {Partner }}$ and $\varepsilon_{1, i}$ would result in an OLS estimate of $\beta_{1}$ that would understate the size of the compensating wage differential for having a split work schedule. Hence, aside from controlling for the educational attainment of the spouse as the channel through which assortative mating could be taking place, ${ }^{13}$ we informally assess whether the partner's type of work schedule $\left(S S^{\text {Partner }}\right)$ is correlated with the error term in the main equation. We do so by gauging its statistical significance in explaining the respondent's wages other than via its impact on the respondent's work schedule. We find that the partner's work schedule is non-statistically significant in explaining the respondent's log hourly wages once we control for the respondent's work schedule itself. ${ }^{14}$ The lack of significance in explaining women's earnings beyond its impact on their work schedules suggests that our instrument may be exogenous to women’s earnings.

\section{2. $\quad$ Results}

The results from estimating equations (2)-(4) for our sample of full-time working women with full-time working partners are displayed in Table 6. We find no evidence of a compensating wage differential for having a split work schedule. Additionally, once we account for the sorting of women into a particular sector based on various observable characteristics, there is no evidence of women employed in the private sector having unobserved characteristics that make them more likely to earn different wages or to have a split work schedule. Instead, age (a proxy for work experience) and education are the best predictors of their log hourly wages. If there is no compensating wage differential for having a more inconvenient work schedule, why would some married women have a split work schedule? Are the women accepting a split work schedule doing so involuntarily? Or is it

\footnotetext{
${ }^{13}$ That is, highly educated individuals with better employment offers may be more likely to have highly educated couples with also good jobs. Accounting for the educational attainment of both partners can then help us purge our estimates from the assortative mating effects occurring via their alike educational attainment.

${ }^{14}$ Results for the sample of full-time working women with full-time working partners -the primary group of interest in this study- are displayed in Table B in the appendix. Similar results for other demographic groups considered later on as a robustness check are available from the authors upon request.
} 
simply that they do not have strong preferences towards a particular work schedule? What do we know about these women? Who are they?

According to the figures in the second column of Table 6 displaying the results from the first-stage instrumental variable regression, married women with fewer children are more likely to have a split work schedule. Additionally, just as hypothesized by Hamermesh (2000), we find evidence of married couples trying to coordinate their work schedules so as to spend more time together. The fact that women with fewer children or with partners with split work schedules are the ones more likely to have the less convenient work schedule clearly indicates that their counterparts with family responsibilities or with partners with continuous work schedules (approximately 80 percent of our sample of women) prefer a continuous work shift. If, despite their preference for a continuous work schedule, women do not receive a compensating wage differential for having a split work schedule, they may have that work schedule involuntarily. In other words, women may be constrained in their job choices and unable to negotiate a compensating wage differential. According to the figures in the column of Table 6, older (more experienced) and more educated counterparts are more likely to choose a public sector job. Hence, younger (less experienced) and less educated women more likely constrained in their work choices are the ones employed in the private sector where split work schedules are concentrated. As such, most women with split work schedules in our sample may be simply unable to negotiate a compensating wage differential.

\subsection{Robustness Checks}

\section{A) $\quad$ Alternative Samples}

As a robustness check, we also carry the analysis for other groups of workers. In particular, because of their even greater family responsibilities, we look at the sample of fulltime working women with full-time working partners and children in Table 7. Subsequently, we examine their full-time working male partners in Table 8 since it is reasonable to think 
that partners may, at various times in their lives, switch their roles and shares of family responsibilities. In both instances, the partner's work sector and work schedule serve as good predictors of the respondent's work sector and work schedule, respectively. Additionally, in the case of the spouse's work schedule, which serves as an instrument for the respondent's own work schedule, we find that it does not help explain hourly wages beyond its impact via the respondent's work schedule when included in the log hourly wage regressions. Hence,

our instrument does not appear to be correlated with the error term in equation (3). More importantly, whether we focus on married women with children or on their male partners, log hourly wages are never significantly impacted by the work schedule. Hence, our results corroborate our previous finding of a lack of a compensating wage differential for a split work schedule.

\section{B) Alternative Definitions of a Split Work Schedule}

Thus far, the information on the type of work schedule comes from respondents' answers to the question: "Do you have a continuous or a split work schedule?" Having a continuous work schedule is assumed to facilitate the reconciliation of family and work responsibilities relative to having a split work schedule. However, this may not always be the case. For instance, school teachers, the majority of whom are women, have split work schedules; yet, they are done working by 5:00 pm, making their work schedules compatible with carrying other family tasks, such as picking up children after school.

Since we have information on the exact hours of work for each individual from the diary, we have depicted in Figure 4 the work schedules of full-time working men and women in our sample. We separate workers according to the type of work schedule reported. It is clear that men and women who report having split work schedules work until later than their counterparts with continuous work schedules. Yet, among women, there is a reasonable fraction of them that have split work schedules and stop working between 5:00 pm and 6:00 
pm. As such, they are able to combine work and family responsibilities to a greater extent than their counterparts with work schedules ending at a later time. This means that our previous measure of a split work schedule does not exclusively encompass work schedules that make it difficult to reconcile work and family responsibilities. Since the purpose of the study is to explore whether there exists a compensating wage differential for having an inconvenient work schedule, including women with more convenient split work schedules can only downward bias the compensating wage differential estimate. Hence, we define a new variable labeled inconvenient work schedule in three different ways. In all instances, workers must report "having a split work schedule”. In addition, they must report working continuously between: (i) 5 pm and 6 pm, (ii) 5 pm and 7 pm, or (iii) 5 pm and 8 pm.

According to the figures in Table 9, about 19 percent of full-time working women in the private sector work between $5 \mathrm{pm}$ and $6 \mathrm{pm}$. However, the percentage working between $5 \mathrm{pm}$ and $7 \mathrm{pm}$ or between $5 \mathrm{pm}$ and $8 \mathrm{pm}$ declines significantly thereafter (to approximately 11 percent and 4 percent, respectively). We re-estimate our model for full-time working women using our three alternative definitions of an inconvenient work schedule and instrumenting the type of work schedule with information on whether their partners also have the same type of work schedule. Partners' work schedules continue to be statistically significant in the first-stage regressions, signaling their high correlation with the female respondents' work schedules. Additionally, we check that the instrument do not help explain women's log hourly wages. ${ }^{15}$ Yet, as in Table 6, we continue to find that our sample of women do not receive a compensating wage differential for having a more inconvenient work schedule.

\footnotetext{
${ }^{15}$ These results are available from the authors.
} 


\section{Discussion of Findings}

We have examined whether full-time working women with full-time working partners are compensated for the inconvenience of having a split work schedule that significantly shortens their evenings at home and possibly interferes with traditional child care tasks. We find that, regardless of whether we address the selection into a particular sector or the endogeneity of the type of work schedule, women in our sample do not appear to be compensated for the disutility of having more inconvenient work hours. Our findings are robust to the use of alternative samples of workers and alternative definitions of an inconvenient work schedule. What may be the explanation for our findings?

Certainly, centralized wage setting via collective bargaining, which in Spain covers more than 80 percent of workers in the economy, clearly constraints the emergence of a compensating wage differential. After all, unless clearly stipulated in the collective bargaining (which is not), it is fairly unlikely for a compensating wage differential to emerge.

In addition, the Spanish labor market, often characterized for its segmented nature (e.g. Toharia and Malo 1999, Amuedo-Dorantes 2000, Davia and Hernanz 2004), may lack one of the assumed characteristics by hedonic wage theory for compensating wage differentials to emerge, i.e. sufficient job mobility. As noted by Rosen (1986), job mobility is a requirement to guarantee that workers sort across firms according to the distinct characteristics of the jobs being offered. If workers cannot easily choose among multiple jobs, as it is the case when the unemployment rate is high and job mobility is limited, a compensating wage differential may not emerge. Instead, workers may be stuck with "take-it or leave-it” employment offers that prevent the appearance of a compensating wage differential. The fact that split work schedules are more prevalent among: (a) men and (b) women with fewer family responsibilities and/or with partners with a similar work schedule, suggests that the vast majority of women in our sample (about 80 percent of them) have a 
clear preference for a continuous work schedule. Yet, they are not compensated for the disutility of having a more inconvenient work schedule. This is not surprising once we find that the women in the private sector, where split work schedules are found, are precisely the least experienced (as proxied by their age) and the least educated. These are, indeed, the group of women more likely to be constrained in their job choices and, as such, unable to negotiate a compensating wage differential.

\section{Summary and Policy Implications}

Conflicts between family and work responsibilities due to the timing of work have been on the rise as the fraction of working women has increased over the past decades. Spain is no exception owing to the impressive growth in female labor force participation over the past two decades and the predominance of the "split work schedule", which requires to be at work in the morning, as well as in the late afternoon/early evening. In an attempt to understand the prevalence of split work schedules, we ask ourselves who has a split work schedule and why. We focus on individuals for whom the reconciliation of work and family responsibilities is more likely to be an issue, such as full-time working couples and, in particular, women. Using data from the Spanish Time Use Survey, we first examine the incidence of split work schedules, which are generally observed among younger (less experienced) workers, as well as among employees without children. Additionally, split work schedules are a feature of the private sector.

Subsequently, we ask ourselves: who are the employees with a split work schedule and why do they choose it? Are they voluntarily choosing that type of work schedule due to their preferences or in exchange for a higher compensation? Or are they simply constrained in their employment choices? To answer these questions, we would ideally use longitudinal data allowing us to follow individuals over time across different jobs to account for unobservable individual level characteristics correlated with work schedules and pay, such as 
productivity. Unfortunately, such data do not exist. Therefore, we proceed by estimating instrumental variable log-wage regressions that account for the self-selection of workers into a private sector job (where split work schedules are mostly found) and for the endogeneity of the type of work schedule. We find that women with fewer family responsibilities or with partners with alike work schedules are more likely to have jobs with split work schedules. Hence, most women in our sample (i.e. about 80 percent) prefer a continuous work schedule. Yet, we fail to find any evidence of a compensating wage differential for having a split work schedule. Our findings are robust to the use of different samples of workers and to alternative definitions of an inconvenient work schedule.

In sum, despite exhibiting a preference for a continuous work schedule, women do not seem to be compensated for the disutility of having a more inconvenient work schedule. In consequence, women appear to be taking jobs with split work schedules involuntarily. Is this contention supported by the data? According to the results from the equation modeling the selection of women into the private sector, where split work schedules are typically found, younger (less experienced) and less educated married women more likely to be constrained in their employment choices are the ones with private sector jobs. Thus, lack of sufficient job choices may explain why we do not observe a compensating wage differential for having a more inconvenient work schedule.

What policy implications stem from our findings? Due to the apparently involuntary nature of split work schedules among full-time working women with family responsibilities, some policy measures could prove helpful in reducing work and family conflicts. The literature has often predicated the value of leave entitlements and the provision of affordable child care in reconciling work and family responsibilities (Hein 2005). We believe that coordinating school and work hours could prove especially helpful in the Spanish case and, therefore, should probably constitute one of the priorities in future collective bargaining 
among the government, workers' unions and employers' organizations. If production requirements call for it, continuous and split work schedules could co-exist along with a corresponding wage differential for the more inconvenient work schedule. The compensating wage differential should then reflect employees' preferences and firms' costs. Alternatively, the government could provide firms with incentives for offering family-friendly work environments via the availability of flexible working times (e.g. compressed work-weeks or staggered working hours) or flexible working place arrangements (e.g. part-time work or teleworking). These measures could prove particularly useful in reducing work and family conflicts in Spain, where a variety of leave entitlements are already in place and where there is a relative good supply of pre-school services for young children, even though their hours tend to be incompatible with employment and rely on an adult being able to stay at home (Lohkamp-Himmighofen 1999). 


\section{References}

Amuedo-Dorantes, Catalina. 2000. "Work Transitions into and out of Involuntary Temporary Employment in a Segmented Labor Market: Evidence from Spain” Industrial Labor Relations Review, 53(2): 309-325.

Angrist, J. D. and A. Krueger. 2001. "Instrumental Variables and the Search for Identification: From Supply and Demand to Natural Experiments” Journal of Economic Perspectives, 15(4): 69-85.

Bentolila, Samuel. 2001. “Las Migraciones Interiores en España”, Documento de Trabajo 2001-07, FEDEA, Madrid.

Davia, Maria A. and Virginia Hernanz. 2004. “Temporary Employment and Segmentation in the Spanish Labour Market: An Empirical Analysis Through the Study of Wage Differentials” Spanish Economic Review, 6: 291-318.

Fernandez, Cristina and Sevilla Sanz, Almudena. 2006. "Social Norms and Household Time Allocation”, ISER Working Paper 2006-38. Colchester: University of Essex.

Hamermesh, Daniel S. 2000. “Togetherness: Spouses' Synchronous Leisure and the Impact on Children", NBER Working Paper Series, no. 7455. Available at http://www.nber.org/papers/w7455.

Hamermesh, Daniel S. and S. Donald. 2007. "The Time and Timing Costs of Market Work”, National Bureau of Economic Research.

Hein, Catherine. 2005. Reconciling work and family responsibilities. Practical ideas from global experience. International Labor Organization, Geneva.

Hwang, Hae-Sing, W. Robert Reed, and Carlton Hubbard. 1992. "Compensating Wage Differentials and Unobserved Productivity” Journal of Political Economy, 100(4): 835-58.

Jimeno, Juan Francisco and Luis Toharia. 1993. "The Effects of Fixed-Term Employment on Wages: Theory and Evidence from Spain”, Investigaciones Económicas, 17(3): 475-94.

Lanfranchi, Joseph, Henry Ohlsson, and Ali Skalli. 2002. "Compensating Wage Differentials and Schedule Work Preferences”, Economics Letters, 74(3): 393-398.

Lohkamp-Himmighofen, M. 1999. "Changing gender legislation: From equal pay to caring”, in L. Hantrais (ed.): Changing gender relations and policy, cross-national research paper (Loughborough, Loughborough University, European Research Center).

Olson, Craig A. 2002. "Do Workers Accept Lower Wages in Exchange for Health Benefits?” Journal of Labor Economics, 20(2): S91-114.

Rapoport, Benoît and Céline Le Bourdais. 2008. "Parental Time and Working Schedules”, Journal of Population Economics, 21: 903-932. 
Rosen, Sherwin. 1986. “The Theory of Equalizing Differences" in Orley Ashenfelter and Richard Layard (eds.) Handbook of Labor Economics, Vol. 1. Amsterdam: Elsevier.

Toharia, Luis and Miguel A. Malo. 1999. "The Spanish Experiment: Pros and Cons of Flexibility at the Margin” in Andersen E. (ed.) Why Deregulate the Labour Market? Oxford University Press. 
Figures 1 to 3

Distributions of the Timing of Work in Various European Countries

Figure 1: Spain

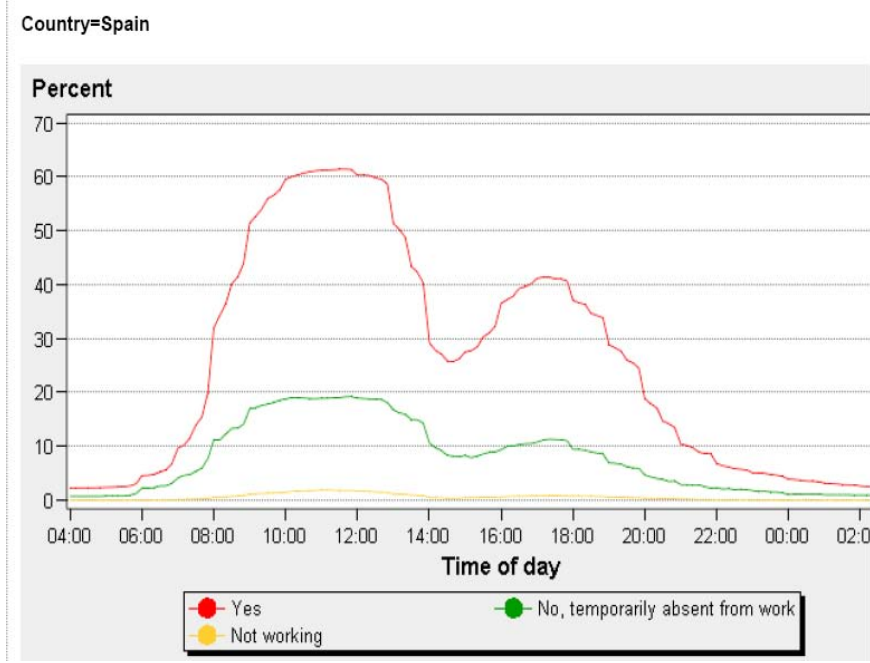

Figure 2: Norway

Country=Norway

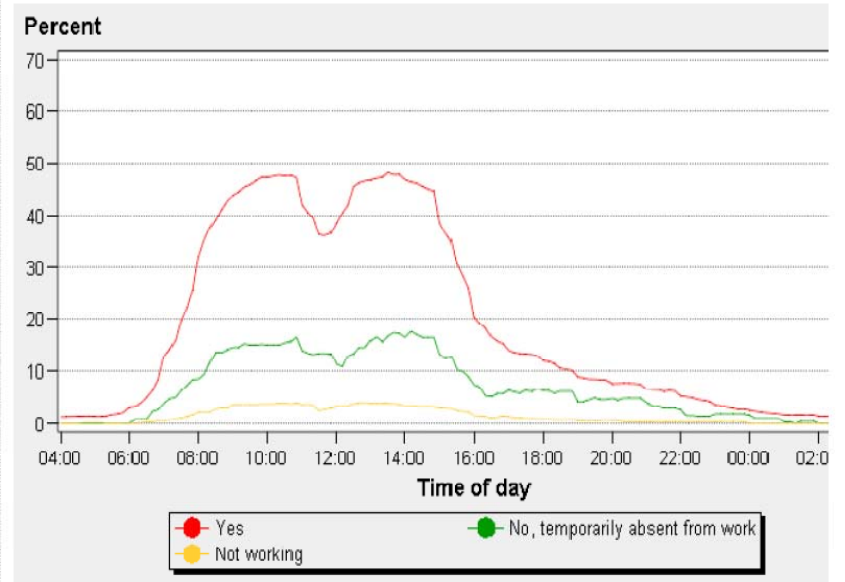

Figure 3: U.K.

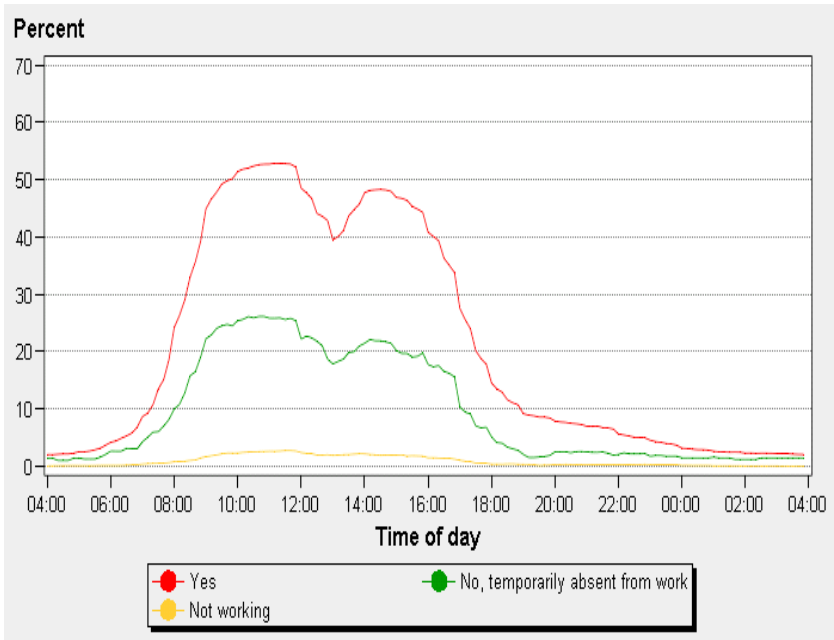


Figure 4

Share of Men and Women Working Throughout the Day by Type of Work Schedule

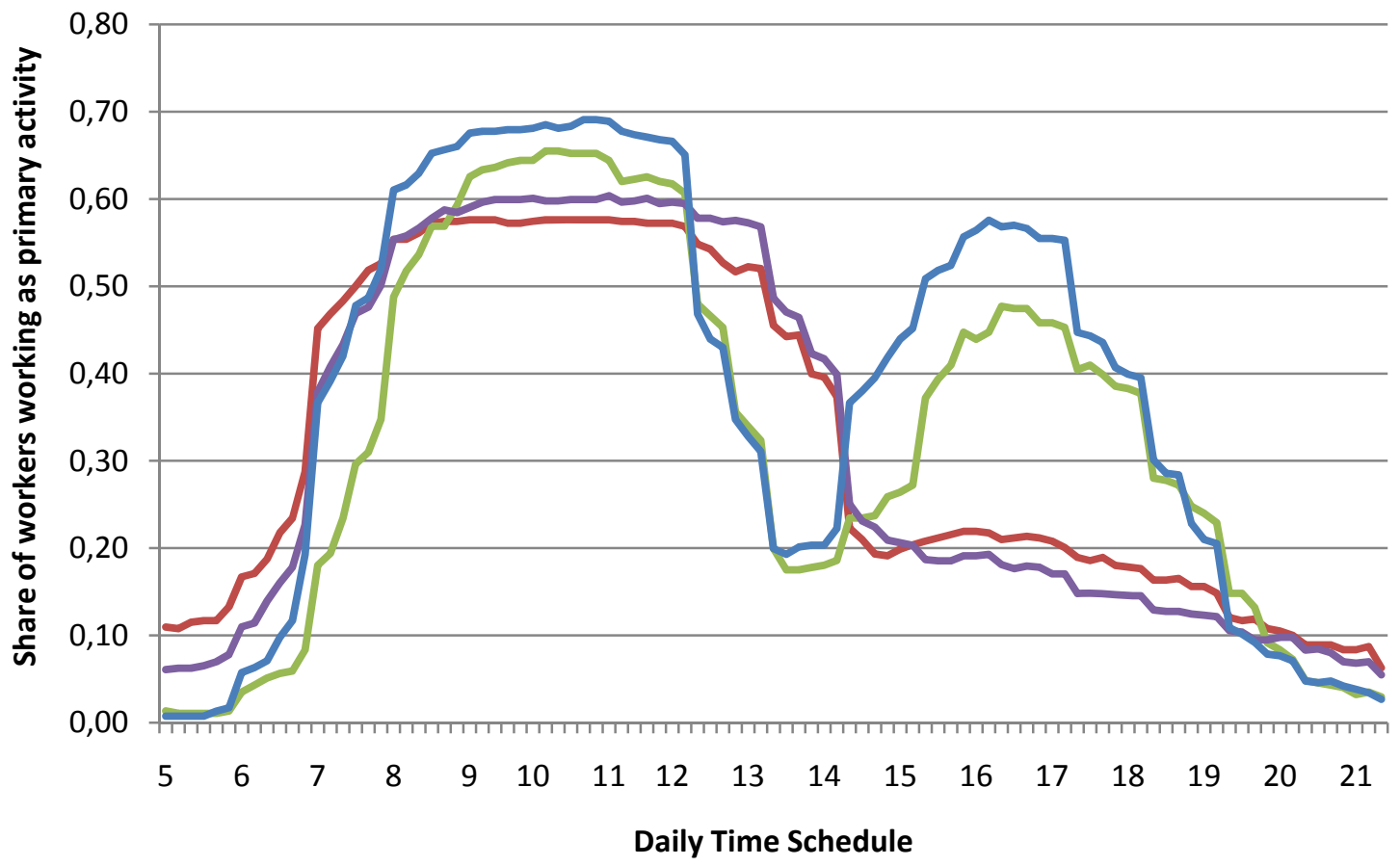

- Men Continuous Shift $\quad \longrightarrow$ Women Split Shift
- Women Continuous Shift $\longrightarrow$ Men Split Shift 
Table 1

Sample Distribution

\begin{tabular}{lcc}
\hline \hline & Men & Women \\
\hline \multirow{2}{*}{ Age } & 40.58 & 40.24 \\
University & $(8.19)$ & $(7.84)$ \\
& 0.26 & 0.30 \\
No Children & $(0.44)$ & $(0.46)$ \\
& 0.31 & 0.31 \\
Private Sector & $(0.46)$ & $(0.46)$ \\
& 0.73 & 0.64 \\
Split working Schedule & $(0.44)$ & $(0.48)$ \\
& 0.49 & 0.35 \\
Log Hourly Wage & $(0.50)$ & $(0.48)$ \\
& 1.96 & 1.80 \\
Observations & $(0.45)$ & $(.53)$ \\
\end{tabular}

Note: The sample consists of full-time working couples 16-64 years of age. 
Table 2

Incidence of Split Work Schedules

\begin{tabular}{|c|c|c|}
\hline \multirow{2}{*}{ Characteristics } & \multicolumn{2}{|r|}{ Women } \\
\hline & Percentage with Split Schedule & Percentage with Split Schedule \\
\hline \multicolumn{3}{|l|}{ Age: } \\
\hline $16-30$ years & 52.5 & 47.2 \\
\hline $31-45$ years & 53.3 & 35.3 \\
\hline More than 45 years & 43.2 & 31.3 \\
\hline \multicolumn{3}{|l|}{ Education: } \\
\hline University & 50.0 & 33.4 \\
\hline Less than University & 46.9 & 36.4 \\
\hline \multicolumn{3}{|l|}{ Children: } \\
\hline No & 51.3 & 40.8 \\
\hline Yes & 48.2 & 33.15 \\
\hline \multicolumn{3}{|l|}{ Sector: } \\
\hline Private & 59.5 & 45.5 \\
\hline Public & 20.9 & 17.4 \\
\hline \multicolumn{3}{|l|}{ Industry: } \\
\hline Agriculture & 45.8 & 50.0 \\
\hline Extractive Industries & 50.3 & 45.4 \\
\hline Construction & 76.3 & 76.9 \\
\hline Trade & 69.5 & 55.6 \\
\hline Hotels & 56.2 & 20.8 \\
\hline Transportation & 43.7 & 32.0 \\
\hline Personal Services & 32.5 & 28.9 \\
\hline Domestic Services & 50.0 & 27.3 \\
\hline \multicolumn{3}{|l|}{ Occupation: } \\
\hline Managers & 59.3 & 91.7 \\
\hline Professionals & 44.8 & 28.3 \\
\hline Technicians and Professionals & 52.8 & 44.4 \\
\hline Clerical support workers & 36.6 & 35.9 \\
\hline Service and sales workers & 37.6 & 35.8 \\
\hline Skilled agricultural/fishery workers & 50.0 & - \\
\hline Craft and related workers & 60.2 & 45.4 \\
\hline Plant/machine operators and assemblers & 42.8 & 21.8 \\
\hline Elementary Occupations & 47.9 & 30.3 \\
\hline
\end{tabular}

Note: The sample consists of full-time working couples 16-64 years of age. 
Table 3

Distribution of Workers with Split Work Schedules in the Public and Private Sector by Occupation

\begin{tabular}{lcccc}
\hline \hline & \multicolumn{2}{c}{ Men } & \multicolumn{2}{c}{ Women } \\
\cline { 2 - 5 } Occupations & \multirow{2}{*}{ Public } & Private & Public & Private \\
\hline Managers & 5.08 & 6.9 & 1.5 & 3.3 \\
Professionals & 52.5 & 11.3 & 52.3 & 8.5 \\
Technicians and other Professionals & 11.9 & 18.6 & 12.3 & 24.8 \\
Clerical support workers & 6.8 & 4.8 & 10.8 & 16.0 \\
Service and sales workers & 6.8 & 7.4 & 9.2 & 19.9 \\
Skilled agricultural/fishery workers & 1.7 & 1.3 & - & - \\
Craft and related workers & 6.8 & 29.2 & 4.6 & 10.5 \\
Plant/machine operators and assemblers & 5.1 & 11.0 & - & 3.9 \\
Elementary Occupations & 3.4 & 9.5 & 9.2 & 13.1 \\
Observations & 59 & 462 & 65 & 306 \\
\hline \hline
\end{tabular}

Note: The sample consists of full-time working couples 16-64 years of age. 
Table 4

Average Log Hourly Wages

\begin{tabular}{lcccc}
\hline \hline \multirow{2}{*}{ Characteristics } & \multicolumn{2}{c}{ Men } & \multicolumn{2}{c}{ Women } \\
\cline { 2 - 5 } & Continuous & Split & Continuous & Split \\
\hline \multirow{2}{*}{ All } & 2.02 & 1.89 & 1.82 & 1.75 \\
& $(0.44)$ & $(0.43)$ & $(0.54)$ & $(0.51)$ \\
Education: & & & & \\
University & 2.37 & 2.31 & 2.21 & 2.16 \\
Non-University & $(0.42)$ & $(0.41)$ & $(0.47)$ & $(0.48)$ \\
& 1.89 & 1.76 & 1.64 & 1.59 \\
Sector: & $(0.38)$ & $(0.35)$ & $(0.47)$ & $(0.43)$ \\
\multirow{2}{*}{ Private } & & & & \\
Public & 1.93 & 1.85 & 1.60 & 1.67 \\
& $(0.43)$ & $(0.41)$ & $(0.53)$ & $(0.45)$ \\
& 2.17 & 2.24 & 2.08 & 2.14 \\
& $(0.43)$ & $(0.45)$ & $(0.41)$ & $(0.59)$ \\
\hline \hline
\end{tabular}

Note: The sample consists of full-time working couples 16-64 years of age. 
Table 5

OLS Log Hourly Wage Regressions

\begin{tabular}{lcccc}
\hline \hline \multirow{2}{*}{ Independent Variables } & \multicolumn{2}{c}{ Women } & \multicolumn{2}{c}{ Men } \\
& Public & Private & Public & Private \\
\hline \multirow{2}{*}{ Split Work Schedule } & $\mathbf{0 . 0 4 4}$ & $\mathbf{- 0 . 0 3 5}$ & $\mathbf{0 . 0 5 7}$ & $\mathbf{- 0 . 0 8 0}^{* * *}$ \\
& $\mathbf{( 0 . 0 6 1 )}$ & $\mathbf{( 0 . 0 3 4 )}$ & $\mathbf{( 0 . 0 5 7 )}$ & $\mathbf{( 0 . 0 3 0 )}^{\circ}$ \\
Age & 0.006 & $0.050^{* *}$ & 0.049 & $0.052^{* * *}$ \\
& $(0.028)$ & $(0.022)$ & $(0.032)$ & $(0.015)$ \\
Age Squared & $-1.23 \mathrm{e}-05$ & $-5.38 \mathrm{e}-04^{* *}$ & $-4.33 \mathrm{e}-04^{* *}$ & $-5.25 \mathrm{e}-04^{* *}$ \\
& $(3.28 \mathrm{e}-04)$ & $(2.69 \mathrm{e}-04)$ & $(3.64 \mathrm{e}-04)$ & $(1.82 \mathrm{e}-04)$ \\
Parent & 0.010 & -0.016 & 0.087 & 0.031 \\
& $(0.048)$ & $(0.039)$ & $(0.057)$ & $(0.032)$ \\
University & $0.422^{* * *}$ & $0.286^{* *}$ & $0.355^{* * *}$ & $0.353^{* * *}$ \\
& $(0.042)$ & $(0.046)$ & $(0.046)$ & $(0.047)$ \\
R-squared & 0.43 & 0.33 & 0.47 & 0.30 \\
N. observations & 351 & 603 & 278 & 764 \\
& & & & \\
\hline \hline
\end{tabular}

Note: The sample consists of full-time working couples 16-64 years of age. There are a total of 1052 couples. All regressions include industry (9) and regional dummies (18 autonomous communities), as well as information on the educational attainment of the partner. *** denotes significance at the 1 percent level, ** denotes significance at the 5 percent level and * denotes significance at the 10 percent level. 
Table 6

Instrumental Variable Regression of Log Hourly Wages

with Selection for Private Sector Employment

Sample: Full-time Working Women with Full-time Working Partners

\begin{tabular}{|c|c|c|c|}
\hline Independent Variables & $\begin{array}{l}\text { Main Equation } \\
\text { IV Regression }\end{array}$ & $\begin{array}{l}\text { First Stage } \\
\text { IV Regression }\end{array}$ & $\begin{array}{l}\text { Selection into Private } \\
\text { Sector Employment }\end{array}$ \\
\hline Split Work Schedule & $\begin{array}{l}-0.147 \\
(0.200)\end{array}$ & - & - \\
\hline Age (ref: <30 years) & & & \\
\hline Aged 31-35 & $\begin{array}{c}0.037 \\
(0.055)\end{array}$ & $\begin{array}{l}-0.008 \\
(0.071)\end{array}$ & $\begin{array}{l}-0.220 \\
(0.245)\end{array}$ \\
\hline Aged 36-40 & $\begin{array}{c}0.067 \\
(0.052)\end{array}$ & $\begin{array}{l}-0.033 \\
(0.071)\end{array}$ & $\begin{array}{l}-0.546^{* *} \\
(0.235)\end{array}$ \\
\hline Aged 41-45 & $\begin{array}{l}0.160^{* *} \\
(0.056)\end{array}$ & $\begin{array}{l}-0.103 \\
(0.078)\end{array}$ & $\begin{array}{l}-0.857^{* *} \\
(0.246)\end{array}$ \\
\hline Aged 46-50 & $\begin{array}{l}0.099^{*} \\
(0.066)\end{array}$ & $\begin{array}{l}-0.104 \\
(0.079)\end{array}$ & $\begin{array}{l}-0.750^{* *} \\
(0.235)\end{array}$ \\
\hline Aged $>50$ & $\begin{array}{l}0.110^{*} \\
(0.073)\end{array}$ & $\begin{array}{l}-0.053 \\
(0.090)\end{array}$ & $\begin{array}{l}-0.797^{* *} \\
(0.236)\end{array}$ \\
\hline N. of children & $\begin{array}{l}-0.017 \\
(0.028)\end{array}$ & $\begin{array}{l}-0.056^{* *} \\
(0.026)\end{array}$ & $\begin{array}{l}-0.063 \\
(0.069)\end{array}$ \\
\hline University & $\begin{array}{l}0.319^{* *} \\
(0.057)\end{array}$ & $\begin{array}{c}0.058 \\
(0.067)\end{array}$ & $\begin{array}{l}-0.555^{* *} \\
(0.126)\end{array}$ \\
\hline Spouse's Schedule & - & $\begin{array}{l}0.165^{* *} \\
(0.043)\end{array}$ & - \\
\hline Spouse's Sector & - & - & $\begin{array}{l}1.007^{* *} \\
(0.126)\end{array}$ \\
\hline Lambda & $\begin{array}{l}-0.042 \\
(0.086)\end{array}$ & $\begin{array}{c}0.097 \\
(0.115)\end{array}$ & - \\
\hline R-squared & 0.24 & 0.08 & \\
\hline N. observations & \multicolumn{2}{|c|}{573} & 923 \\
\hline
\end{tabular}

Notes: The sample consists of full-time working women with full-time working partners 16-64 years of age. All regressions include industry (9) and regional dummies (18 autonomous communities), as well as information on the age and educational attainment of the partner. Robust standard errors are in parentheses. $* *$ denotes significance at the 5 percent level. * denotes significance at the 10 percent level. 
Table 7

Instrumental Variable Regression of Log Hourly Wages

with Selection for Private Sector Employment

Sample: Full-time Working Mothers with Full-time Working Partners

\begin{tabular}{|c|c|c|c|}
\hline Independent Variables & $\begin{array}{l}\text { Main Equation } \\
\text { IV Regression }\end{array}$ & $\begin{array}{c}\text { First Stage } \\
\text { IV Regression }\end{array}$ & $\begin{array}{l}\text { Selection into Private } \\
\text { Sector Employment }\end{array}$ \\
\hline Split Work Schedule & $\begin{array}{l}-0.281 \\
(0.371)\end{array}$ & - & - \\
\hline Age (ref: <30 years) & & & \\
\hline Aged 31-35 & $\begin{array}{c}0.055 \\
(0.083)\end{array}$ & $\begin{array}{c}0.022 \\
(0.095)\end{array}$ & $\begin{array}{l}-0.284 \\
(0.418)\end{array}$ \\
\hline Aged 36-40 & $\begin{array}{c}0.021 \\
(0.082)\end{array}$ & $\begin{array}{l}-0.003 \\
(0.093)\end{array}$ & $\begin{array}{l}-0.525 \\
(0.400)\end{array}$ \\
\hline Aged 41-45 & $\begin{array}{l}0.156^{*} \\
(0.082)\end{array}$ & $\begin{array}{l}-0.064 \\
(0.100)\end{array}$ & $\begin{array}{l}-0.917^{* *} \\
(0.413)\end{array}$ \\
\hline Aged 46-50 & $\begin{array}{c}0.128 \\
(0.091)\end{array}$ & $\begin{array}{l}-0.074 \\
(0.104)\end{array}$ & $\begin{array}{l}-0.587^{* *} \\
(0.414)\end{array}$ \\
\hline Aged $>50$ & $\begin{array}{c}0.061 \\
(0.134)\end{array}$ & $\begin{array}{c}0.030 \\
(0.207)\end{array}$ & $\begin{array}{l}-1.513^{* *} \\
(0.556)\end{array}$ \\
\hline N. of children & $\begin{array}{l}-0.052 \\
(0.051)\end{array}$ & $\begin{array}{l}-0.066^{*} \\
(0.042)\end{array}$ & $\begin{array}{l}-0.053 \\
(0.111)\end{array}$ \\
\hline University & $\begin{array}{l}0.436^{* *} \\
(0.097)\end{array}$ & $\begin{array}{c}0.035 \\
(0.092)\end{array}$ & $\begin{array}{l}-0.638^{* *} \\
(0.157)\end{array}$ \\
\hline Spouse's Schedule & - & $\begin{array}{l}0.189^{* *} \\
(0.052)\end{array}$ & - \\
\hline Spouse's Sector & - & - & $\begin{array}{l}0.966^{* *} \\
(0.152)\end{array}$ \\
\hline Lambda & $\begin{array}{l}-0.068 \\
(0.135)\end{array}$ & $\begin{array}{c}0.096 \\
(0.146)\end{array}$ & - \\
\hline R-squared & 0.24 & 0.08 & \\
\hline N. observations & \multicolumn{2}{|c|}{381} & 650 \\
\hline
\end{tabular}

Notes: The sample consists of full-time working mothers with full-time working partners 16-64 years of age. All regressions include industry (9) and regional dummies (18 autonomous communities), as well as information on the age and educational attainment of the partner. Robust standard errors are in parentheses. $\quad * *$ denotes significance at the 5 percent level. * denotes significance at the 10 percent level. 
Table 8

Instrumental Variable Regression of Log Hourly Wages

with Selection for Private Sector Employment

Sample: Full-time Working Male Partners (of Full-time Working Women in Table 6)

\begin{tabular}{|c|c|c|c|}
\hline Independent Variables & $\begin{array}{l}\text { Main Equation } \\
\text { IV Regression }\end{array}$ & $\begin{array}{c}\text { First Stage } \\
\text { IV Regression }\end{array}$ & $\begin{array}{l}\text { Selection into Private } \\
\text { Sector Employment }\end{array}$ \\
\hline Split Work Schedule & $\begin{array}{l}-0.147 \\
(0.230)\end{array}$ & - & - \\
\hline Age (ref: <30 years) & & & \\
\hline Aged 31-35 & $\begin{array}{c}0.062 \\
(0.061)\end{array}$ & $\begin{array}{l}0.143^{* *} \\
(0.074)\end{array}$ & $\begin{array}{l}-0.113 \\
(0.321)\end{array}$ \\
\hline Aged 36-40 & $\begin{array}{l}0.109^{*} \\
(0.067)\end{array}$ & $\begin{array}{l}0.175^{* *} \\
(0.074)\end{array}$ & $\begin{array}{l}-0.082 \\
(0.313)\end{array}$ \\
\hline Aged 41-45 & $\begin{array}{l}0.155^{* *} \\
(0.741)\end{array}$ & $\begin{array}{l}0.206^{* *} \\
(0.072)\end{array}$ & $\begin{array}{l}-0.133 \\
(0.302)\end{array}$ \\
\hline Aged 46-50 & $\begin{array}{l}0.207^{* *} \\
(0.057)\end{array}$ & $\begin{array}{c}0.063 \\
(0.074)\end{array}$ & $\begin{array}{l}-0.344 \\
(0.302)\end{array}$ \\
\hline Aged $>50$ & $\begin{array}{l}0.119^{* *} \\
(0.061)\end{array}$ & $\begin{array}{c}0.101 \\
(0.075)\end{array}$ & $\begin{array}{l}-0.550^{*} \\
(0.303)\end{array}$ \\
\hline N. of children & $\begin{array}{c}0.010 \\
(0.021)\end{array}$ & $\begin{array}{l}-0.041^{* *} \\
(0.022)\end{array}$ & $\begin{array}{l}-0.112^{*} \\
(0.061)\end{array}$ \\
\hline University & $\begin{array}{l}0.354^{* *} \\
(0.062)\end{array}$ & $\begin{array}{c}0.131 \\
(0.051)\end{array}$ & $\begin{array}{l}-0.283^{* *} \\
(0.136)\end{array}$ \\
\hline Spouse's Schedule & - & $\begin{array}{l}0.154^{* *} \\
(0.036)\end{array}$ & - \\
\hline Spouse's Sector & - & - & $\begin{array}{l}0.853^{* *} \\
(0.122)\end{array}$ \\
\hline Lambda & $\begin{array}{c}0.110 \\
(0.092)\end{array}$ & $\begin{array}{c}0.019 \\
(0.115)\end{array}$ & - \\
\hline R-squared & 0.24 & 0.08 & \\
\hline N. observations & \multicolumn{2}{|c|}{751} & 1031 \\
\hline
\end{tabular}

Notes: The sample consists of the full-time working male partners of the full-time working women 1664 years of age. All regressions include industry (9) and regional dummies (18 autonomous communities), as well as information on the age and educational attainment of the partner. Robust standard errors are in parentheses. ** denotes significance at the 5 percent level. * denotes significance at the 10 percent level. 
Table 9

Instrumental Variable Regression of Log Hourly Wages with Alternative Definitions of a Split Work Schedule

\section{Type of Split Work Schedule}

\begin{tabular}{lcc}
\hline & & \\
Alternative Definition $\mathbf{1}$ & 0.187 & -0.454 \\
Split + at least from 5 to $6 \mathrm{pm}$ & $(0.39)$ & $(0.883)$ \\
& & \\
Alternative Definition 2 & 0.113 & -0.427 \\
Split + at least from 5 to 7 pm & $(0.316)$ & $(0.490)$ \\
Alternative Definition 3 & 0.038 & 4.343 \\
Split + at least from 5 to 8 pm & $(0.191)$ & $(51.2)$ \\
\end{tabular}

Notes: The sample consists of full-time working women with full-time working partners 16-64 years of age. We run separate estimations for each definition of the dependent variable in the main log hourly wage regression. All regressions include also age and age square, university, private sector, number of kids, industry (9) and regional dummies (18 autonomous communities), as well as information on the educational attainment of the partner. Robust standard errors are in parentheses.

* denotes significance at the 10 percent level 


\section{Appendix}

Table A

Instrumental Variable Log Hourly Wage Regression

\begin{tabular}{lc}
\hline \hline Variables & Coefficient (S.E.) \\
\hline Spouse's Sector & $\mathbf{0 . 0 0 2}$ \\
& $\mathbf{( 0 . 0 6 9 )}$ \\
R-squared & 0.279 \\
N. observations & 573 \\
\hline \hline
\end{tabular}

Note: The sample consists of full-time working women with full-time working partners 16-64 years of age. The regression includes age, age square, a university dummy, a dummy variable indicating whether the respondent is a parent, industry (9) and regional dummies (18 autonomous communities), as well as information on the educational attainment of the partner and the selection parameter lambda. ${ }^{* *}$ denotes significance at the 5 percent level, and * denotes significance at the 10 percent level.

Table B

OLS Log Hourly Wage Regression

\begin{tabular}{lc}
\hline \hline Variables & Coefficient (S.E.) \\
\hline Spouse's Schedule & $\mathbf{- 0 . 0 2 0}$ \\
& $\mathbf{( 0 . 0 3 4 )}$ \\
R-squared & 0.294 \\
N. observations & 573 \\
\hline \hline
\end{tabular}

Note: The sample consists of full-time working women with full-time working partners 16-64 years of age. Along with information regarding the respondent's own work schedule, the regression includes age, age square, a university dummy, a dummy variable indicating whether the respondent is a parent, industry (9) and regional dummies (18 autonomous communities), as well as information on the educational attainment of the partner. ${ }^{* *}$ denotes significance at the 5 percent level, and * denotes significance at the 10 percent level. 